\title{
Blockchain Technology Adoption by Malaysian Higher Education Institutes: A Perspective of Integrated Tam Model and Toe Framework
}

\author{
Waleed Iftikhar ${ }^{1, *}$ Daniel Mago Vistro ${ }^{2}$ Zunair Mahmood ${ }^{3}$ \\ ${ }^{1,2,3}$ Asia Pacific University, Malaysia \\ *Corresponding author. Email: Waleed_khan11@live.com
}

\begin{abstract}
The purpose of this research is to identify and investigate the factors that influence Blockchain technology adoption in Malaysian higher education sector. This research has proposed a theoretical framework for Blockchain technology adoption based on Integrated TAM model and TOE framework constructs. The seven factors examined in this research are relative advantage, perceived ease of use, perceived usefulness, scalability concern, top management support, competitive pressure and regulatory policy. Factors are categorized in the Technological, organizational and environmental context. A questionnaire-based survey was used to collect the primary data for this research, from five Malaysian higher education institutes. Hypothesis for this research were derived using the proposed research framework and previously published literature, and further tested using multiple linear regression. The findings of the statistical analysis reveal that, perceived usefulness, competitive pressure and top management support have a significant and positive influence on Malaysian higher education institutes intention to adopt Blockchain technology. This research was performed in the Malaysian higher education sector, so this may limit the generalizability of the relevant findings. The findings of this research provide a better understanding of which technological, organizational and environmental factors affect the Blockchain adoption process in the Malaysian higher education institutes. This research contributes to the theoretical body of knowledge of the technology adoption, by examining unique external variables with an integrated TAM model and TOE framework approach.
\end{abstract}

Keywords: Blockchain adoption, TAM model, TOE framework, Malaysian HEI's.

\section{INTRODUCTION}

Information technology (IT) plays an important role for any organization in the current business environment [1]. Fierce competitive business environment demands from an organization to adopt disruptive technologies in order to sustain in the market. It is very essential for an organization to adopt appropriate technology that can be helpful in achieving competitive advantage and enhancing business operations and their performance [2] [82-89]. Role of IT in the higher education sector and its advantages for educational perspectives are greatly noted. Universities around the globe have faced strong competition in terms of student's intake and educational services. Major reason of this strong competitive environment originates due to the increase in globalization and recent rapid progress in IT [3]. Universities around the world are operating in a very dynamic and complex business environment, this has forced universities to not only focus on their core educational activities like research and education but also to adopt innovative tools and technologies that can help in decision making process [4]. Adopting Blockchain technology can be a source of innovation for the universities to improve their business process and decision making capability [5] [90-93].

The concept of Blockchain was first introduced by Satoshi Nakamoto in 2008 [6]. Although it is worth noted, that the author did not use Blockchain word once in the paper, rather it was acknowledged as bitcoin or cryptocurrency. While Blockchain is a distributed database that keep records in the form of list of chains coupled in blocks [7].

Blockchain technology is considered as a base for distributed ledgers, that can be used for innovative mechanism of decentralized and transparent transactions 
in various sectors [8]. Furthermore, Author [9], declared Blockchain as a similar class of innovation like internet.

Blockchain technology can truly revolutionize the higher education sector by shifting its traditional paradigm[10]. Through utilizing Blockchain technology higher learning institutes can make their degree issuing process more transparent and efficient.

Blockchain technology can be an effective solution to the fake degrees issue in Malaysian higher education sector[11]. Although Blockchain technology has been embraced by the Malaysian financial services industry, higher education sector of Malaysia is yet to explore the potential of Blockchain technology [12]. However, Malaysian government is actively taking steps to utilize Blockchain technology for the education perspective. The education Ministry of Malaysia has setup a university consortium on Blockchain technology which includes six public universities of Malaysia, and the sole purpose is to launch a degree issuance and verification system[13]. Based on the research conducted in University of Malaya, Blockchain technology is still in its infancy phase and with time challenges in its adoption across various industries would come up. These challenges would range from technological to regulatory context and surely with progress their solution will be highlighted [14]. Malaysian industry is open to various applications Blockchain technology has to offer [15], with regards to this, Malaysian industry-government group of high technology (MIGHT) has declared the Blockchain technology adoption by 2025 [16]. University Malaysia Pahang (UMP) has launched a system called as Valid8, which is based on Blockchain technology, the sole purpose of this system is to make their degrees tamper-proof [17]. Limkokwing university Malaysia and University Tunku Abdul Rehman (UTAR) have also shown interest in Blockchain technology and are actively involved in performing research activities to integrate Blockchain as a part of their system. Currently financial, healthcare and audit firms are prominent examples of Blockchain adoption in Malaysia, and higher education sector is yet to explore it [18].

With the established facts above, this study seeks to identify the factors influencing Blockchain adoption in Malaysian higher education institutes. Major aim of this study is to identify factors related to technological, organizational and environmental context that can influence Malaysian higher education institutes intention to adopt Blockchain technology in their educational settings. Identified factors will be ranked based on their criticality, so that it is helpful for universities to prioritize these aspects based on their significance.

\section{LITERATURE REVIEW}

Blockchain technology has the great potential to be applied in the higher education sector. Several universities have utilized Blockchain to design and implement solutions related to higher learning. Majority of them have utilized bitcoin version of Blockchain to develop their solutions [19]. The national university of La Plata (UNLP) has been working on creating a framework, which would be based on Blockchain for the purpose of verification and validation of the academic documents and achievements. This higher education solution utilized Blockchain and some aspects of cryptography, in order to authorize and deliver diplomas for their students. This solution only deals with the certificate issuing using bitcoin version of Blockchain, it does not entertain the problem of gained marks/credits verification, for the respective student if he/she has completed the degree [20]. One similar solution is also being designed by CESYT college in Argentina[21], [22].

The Leonardo da Vinci Engineering School in Paris, declared in 2016 that they will certify their degrees using a platform that will utilize bitcoin Blockchain. They collaborated with a company named as Paymium, which operates as a startup in France. Currently they have not introduced any prototype to test this solution [23]. Holberton school of software engineering in San Francisco, showed their interest in the technology and declared in 2015, that they would use Blockchain to engage and help potential employers regarding the verification of the academic achievements [24]. The university of Nicosia has been declared as the first university to officially adopt Blockchain for the verification of their degrees. Moreover, university has the privilege to be the first higher education institute that accepted bitcoin as a payment method [25].

Research in the field of Blockchain and its applicability in the higher education sector is rapidly growing. The Open university in UK, initiated a project OpenBlockchain, for the purpose of highlighting the technology's strength and its advantages in this field[26]. Many universities have initiated to start teaching Blockchain in the degree level. Woolf University was initiated at the Oxford University and its claims to be the first Blockchain-based learning institute. It is an online learning institute which works on the basis of an application, which will enable different academics to market their expertise. Students will be able to select their degree level courses and its credits, while the dues will be paid using Woolf tokens which is based on cryptocurrency [27]. Smart contracts that are based on Blockchain, will be used to store educational documents, record each course attendance and formalizing the payments. It is quite visible that Blockchain will change the whole scenario of how the things will be managed at this online university, where universities management has to deploy different officers and system operators to mediate between students and their respective lecturers. Most notable advantage of this Blockchain based university will be that, students will have to pay less 
module fees and the academic employees will have higher pays [28].

According to the study by [29], Media Lab of Massachusetts Institute of Technology (MIT) is the only entity that has developed a complete academic credentialing platform that is based on Blockchain. Media lab team has utilized bitcoin instead of Ethereum as they think it is more powerful and can survive longer as compare to Ethereum. MIT Media Lab introduced a mobile application in 2015 for the purpose of issuing digitalized educational certificates to the students, this electronic system is called as Blockcerts. MIT media lab collaborated with a software company Learning Machine (LM) to initiate its maiden Blockchain-based certificates to the team of IT innovators[30]. They even went ahead, by issuing Blockchain-based diplomas to the students of Sloan School of business. Furthermore, [31] claims that MIT would get the feedback regarding this platform from the students who will graduate in the year 2018, while it will learn from the existing Blockchain projects to further utilize the use of Blockchain in its services.

\subsection{Technology adoption theories and models}

Based on the findings of [32], adoption can be divided into three different stages, individual, organizational and combined. While various researchers have critically discussed that UTAUT, TRA and TPB were completely focused on identifying perceived adoption at the individual level and less focused on the organizational point of view of the technology adoption [33]. Based on that, TAM integrated with TOE framework is widely adopted for analyzing adoption of a new technology in the organizational context [34]. TAM has been regarded as the most accurate and efficient model to evaluate organizational view of technology adoption [35]. Based on the critical review of various researchers, TAM model has been found as the most attractive theory in the literature, and TAM model and its integrated versions with other models have been widely accepted as a valid method of empirical and theory-based studies. In fact, this approach of modified TAM is greatly adopted by researchers in comparison to other existing model and theories [36]. Furthermore, TAM model has some advantages like, it's simple and efficient design enables researchers to predict the wide range of individual's perception about the technology adoption with regards to organizational level, also has been accepted as the most dominant theory for examining technology adoption at the user level [37].

TOE framework on the other side, has gained a notable appreciation in the context of examining technology adoption at the organizational level. Various researchers have tested its determinants for the adoption purpose in the context of different technologies[38]. This organizational based theory covers factors that are distributed over technological, organizational and environmental prospects of the technology adoption. TOE framework enables researchers to examine the adoption of a new technology and its process that can be influenced by technological, organizational and environmental variables [39], [40].

TOE framework major constructs technology, organization and environment has made this framework more significant than other similar theories and models in the literature. TOE framework has been regarded as more effective than Innovation diffusion theory (IDT) which only covers the technology and organizational variables of the technology adoption [41]. Also, TOE framework is flexible in terms of industry application and organization size[42]. Based on the findings of [43], this framework has been greatly examined in technology adoption research works and has produced empirical benefits that are also consistent. Moreover, Researchers [44], further added their value to this perspective, as they reported that this framework's usefulness has been greatly validated in the published researches for the purpose of technology adoption in an organization. Hence, TOE framework is utilized in this research for theoretical perspective and factors identification.

\subsection{Determinants of technology adoption: In the context of HEI's}

A research was performed in Saudi Arabian universities by [45], in the context of cloud computing adoption. They identified factors that would influence technology adoption in the universities based on TOE framework. They examined factors based on Technology, organization and environment as independent variables and cloud computing adoption as the dependent variable. They conducted an online survey in which they sent emails to key decision makers of different universities. Based on their results, relative advantage, complexity and regulatory policy were considered as one of the most significant factors that would influence Blockchain adoption in the sample universities. A similar study was conducted by [46], in which IT professionals were used as a sample of data collection. In this research, TOE framework was utilized and top management was declared as the only determinant of cloud computing adoption in the context of Saudi Arabia institutes.

Researchers [47], conducted a study on cloud-based service adoption in higher education institutes of Malaysia. Their study adopted TOE model for identifying major determinants of technology adoption based on technology, organization and environment context. Based on their findings, Top management support, relative advantages and competitive pressure were one of the significant factors that can impact technology services adoption in higher education institutes of Malaysia. Moreover, researchers [48] emphasized on the role of top management and its 
support for the implementation of the new technology in higher education institutes of Malaysia. Their findings concluded that, organizational support plays a key role in successful implementation of a technology in higher education institutes.

An online survey was conducted by [49], to identify the factors that will influence academic librarian's intention to adopt mobile technology in their operational environment. They proposed a research model based on integrated TAM-TOE framework. Technology, organization and environment constructs were extracted from TOE framework, while perceived ease of use and perceived usefulness were extracted from basic TAM model to act as mediating variables between the identified factors and mobile technology adoption variable. They performed a regression analysis to extract the most critical influencing factors of mobile technology adoption among academic librarians. Technology compatibility, management support and relative advantage were found as the most significant factors for the adoption of the respective technology. Furthermore, PEOU and PU directly influence technology adoption among academic librarians.

According to the findings of Researcher [50], many innovative use cases have been developed and are functional by utilizing the distributed and secure environment of Blockchain. But, with time and experience bitcoin version of Blockchain has come up with challenges in context of scalability and security [51], [52]. Based on the study of [53] Blockchain use-cases have come up with limitations in the decentralization of the storage entity. Furthermore, for Blockchain to be adopted on a wider scale, there is a need to improve the scalability of the present design.

\section{RESEARCH METHODOLOGY}

Empirical approach will be adopted for this research, this approach will help to develop a research structure to review previous published literatures and identify the factors that would influence technology adoption in Higher education institutes of Malaysia. Empirical study is very helpful in technology adoption process as empirical results can be used to study the impact of factors that will be identified [54], [55]. Developed research structure would be helpful to answer all the research questions of the study. Furthermore, quantitative method is used for this research. As quantitative method is based on structured and validated data collection techniques while qualitative method gives responses that are open-ended and are reflections [56].

\subsection{Proposed Research Framework}

Research framework for this study has been developed using the integrated approach of TAM model and TOE framework. Integrated approach of using TAM model constructs and TOE framework constructs has been widely acknowledged and validated by the researchers in the technology adoption studies [36], [49], [57]-[59]. Major constructs of the proposed research framework have been identified from the critical review of the published literature in the technology adoption field. This proposed framework will be helpful in studying the higher education institutes intention to adopt Blockchain based on the identified external factors.

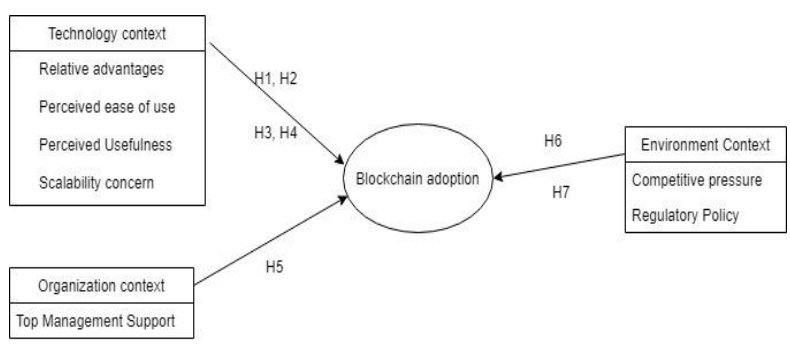

Figure 1 Proposed Research framework

\subsection{Data Analysis and hypothesis testing}

Statistical package for the social sciences (SPSS) will be used for the purpose of data analysis. Once the data is collected it is required to test its reliability, for this purpose Cronbach's Alpha technique will be adopted. Cronbach's alpha is used as an index of reliability and is greatly practiced as an objective measure of reliability. Alpha estimates are easier to measure as compare to other measures like (Test retest reliability estimates), because it is very useful when the study is based on multiple items [60], [61]. Independent variables are the factors identified in the proposed framework based on technological, organizational and environmental context while dependent variable is Blockchain adoption in higher education institutes of Malaysia. Cronbach's Alpha technique will help to analyze the data and decide the consistency among the items and responses of the questionnaire. Online questionnaire will be used for the data collection, and google survey form is chosen for constructing the survey as it is a widely adopted tool by academic researchers [62]. Furthermore, links would be sent to the selected sample using emails.

Multiple regressions would be performed to indicate the predictability of the dependent variable (Blockchain technology adoption) using the independent variable values. Statistical importance of every identified variable is easier to analyze using multiple regression method. Lastly, stepwise technique will be used to highlight the most critical factors from the identified factors (variables) that will have the greatest influence on adoption of the technology in higher education institutes of Malaysia. Stepwise regression is widely practiced by researchers after performing multiple regressions to avoid misleading regression about the importance of variables. 


\section{RESULTS AND DISCUSSION}

Quantitative method is used to collect and analyze the data in this study. Online questionnaire survey was distributed through emails among 200 participants, which includes IT/management staff and faculty staff of the sample universities. Relevant universities were selected based on the fact, that either they have adopted Blockchain or they are currently in the process of adopting Blockchain. Following 5 universities were selected as the sample for distributing the survey, Universiti Tunku Abdul Rahman (UTAR), University Malaysia Pahang (UMP), University of Malaya (UM), University of Technology, Malaysia (UTM), and International Islamic University, Malaysia (IIUM). Graphical representation of the response rate is shown below.

Overall response rate of the questionnaire survey was $22 \%$ as only 44 participants out of 200 filled the questionnaire correctly. Response rate of the survey was quite low, as majority of the universities in the sample are public universities, and it is difficult to reach lecturers and IT staff of the public universities due to time constraints. While, the responses collected are still sufficient enough to perform a quantitative analysis in the SPSS. Based on the collected data, $68.1 \%$ of the responses came from UTAR, UMP and UTM with equal proportion of $22.7 \%$ each. Furthermore, $20.5 \%$ responses came from IIUM and $11.4 \%$ of the responses came from UM and being the lowest in the sample category.

Table 1. Reliability Analysis

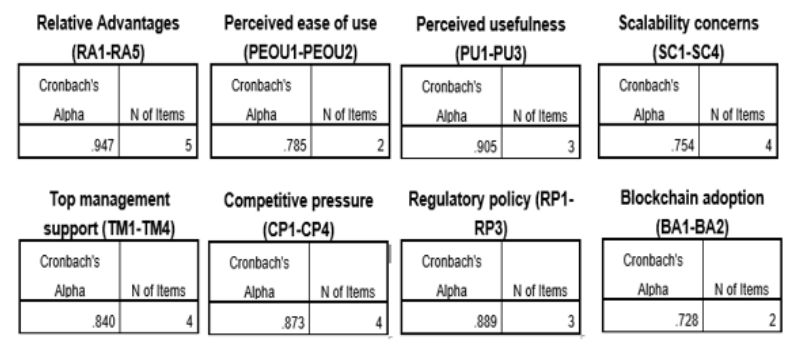

Variables perceived ease of use (PEOU), Scalability concerns (SC), Top management support (TM), Competitive pressure (CP), Regulatory policy (RP) and Blockchain adoption (BA) have Cronbach's alpha value between 0.7-0.9. These variables and their items have shown acceptable range of reliability. While the variables relative advantages (RA) and Perceived usefulness (PU) have resulted a Cronbach's alpha value of greater than 0.9 , hence these variables and their items are highly reliable. Based on the results of Cronbach's alpha, it can be deduced that all the items in the questionnaire are reliable enough for conducting further analysis.
Table 2. Multiple regression Analysis

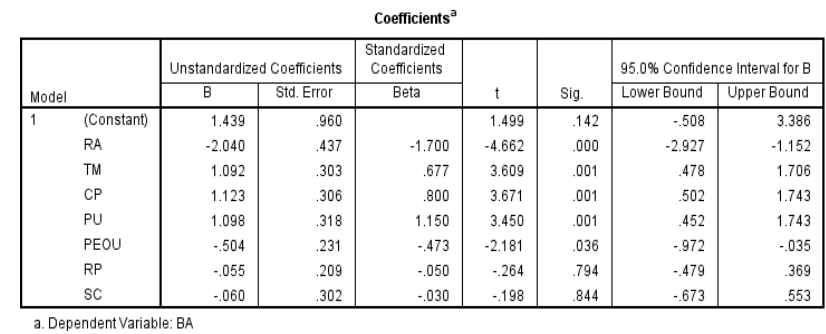

The general form of equation derived from the regression model to predict the dependent variable (BA) from the independent variables (RA, PEOU, PU, SC, TM, CP, RP) is:

Predicted $(\mathrm{BA})=1.439-(2.040 \times \mathrm{RA})-(.504 \times \mathrm{PEOU})$ $+(1.098 \times \mathrm{PU})-(.060 \times \mathrm{SC})+(1.092 \times \mathrm{TM})+(1.123 \times$ $\mathrm{CP})-(.055 \times \mathrm{RP})$

Table 3. Stepwise regression (Model summary and ANOVA statistics

\begin{tabular}{|l|l|r|r|r|}
\hline Model & R & R Square & $\begin{array}{c}\text { Adjusted R } \\
\text { Square }\end{array}$ & $\begin{array}{c}\text { Std. Error of } \\
\text { the Estimate }\end{array}$ \\
\hline 1 & $.510^{\mathrm{a}}$ & .260 & .242 & 1.05745 \\
2 & $.576^{\mathrm{b}}$ & .332 & .300 & 1.01681 \\
3 & $.645^{\circ}$ & .416 & .372 & .96279 \\
4 & $.708^{\mathrm{d}}$ & .502 & .451 & .90060 \\
5 & $.791^{\mathrm{e}}$ & .625 & .576 & .79109 \\
\hline
\end{tabular}
a. Predictors: (Constant), CP
b. Predictors: (Constant), CP, TM
c. Predictors: (Constant), CP, TM, RA
d. Predictors: (Constant), CP, TM, RA, PEOU
9. Predictors: (Constant), CP, TM, RA, PEOU, PU

ANOVA ${ }^{2}$

\begin{tabular}{|c|c|c|c|c|c|c|}
\hline & & $\begin{array}{l}\text { Sum of } \\
\text { Squares }\end{array}$ & di & Mean Square & $\mathrm{F}$ & Sig. \\
\hline \multirow[t]{3}{*}{1} & Regression & 16.507 & 1 & 16.507 & 14.762 & $.000^{\mathrm{b}}$ \\
\hline & Residual & 46.965 & 42 & 1.118 & & \\
\hline & Total & 63.472 & 43 & & & \\
\hline \multirow[t]{3}{*}{2} & Regression & 21.081 & 2 & 10.541 & 10.195 & $.000^{\circ}$ \\
\hline & Residual & 42.390 & 41 & 1.034 & & \\
\hline & Total & 63.472 & 43 & & & \\
\hline \multirow[t]{3}{*}{3} & Regression & 26.393 & 3 & 8.798 & 9.491 & $.000^{\mathrm{d}}$ \\
\hline & Residual & 37.078 & 40 & .927 & & \\
\hline & Total & 63.472 & 43 & & & \\
\hline \multirow[t]{3}{*}{4} & Regression & 31.840 & 4 & 7.960 & 9.814 & $.000^{\circ}$ \\
\hline & Residual & 31.632 & 39 & 811 & & \\
\hline & Total & 63.472 & 43 & & & \\
\hline \multirow[t]{3}{*}{5} & Regression & 39.690 & 5 & 7,938 & 12.684 & $.000^{+}$ \\
\hline & Residual & 23.782 & 38 & .626 & & \\
\hline & Total & 63.472 & 43 & & & \\
\hline \multicolumn{7}{|c|}{ a. Dependent Variable: BA } \\
\hline \multicolumn{7}{|c|}{ b. Predictors: (Constant), CP } \\
\hline \multicolumn{7}{|c|}{ c. Predictors: (Constant), CP, TM } \\
\hline \multicolumn{7}{|c|}{ d. Predictors: (Constant), CP, TM, RA } \\
\hline \multicolumn{7}{|c|}{ e. Predictors: (Constant), CP, TM, RA, PEOU } \\
\hline & & $T_{1}$ & & & & \\
\hline
\end{tabular}

Based on the outcome of the stepwise regression method, there are total 5 iterations and, in each iteration, separate models are created. In each model, a significant variable is added each time to check the predictability on the dependent variable. In model 1, CP variable has been selected as the most important variable, which also explains the highest variance $(26 \%)$ of Blockchain adoption. While subsequently, in the model 5, all the important variables are selected based on their rank and significance that they have for predicting the dependent 
variable. Significant variables selected in the model 5 are in this rank respectively $\mathrm{CP}, \mathrm{TM}, \mathrm{RA}, \mathrm{PEOU}$ and PU. While, the variables $\mathrm{SC}$ and $\mathrm{RP}$ are rejected by the stepwise method as they do not explain sufficient variance for the dependent variable. In the model 5 , the "R square" value is .625 which means all the significant variables explain $62.5 \%$ of the variance in Blockchain adoption. This result is approximately similar to the outcome of simple multiple linear regression as; $62.7 \%$ variance is explained in that approach. Thus, this also validates the outcome of both methods used. In the "ANOVA" statistics of the stepwise method, all the resulted scenarios have a "sig." value $(p<0.0001)$, which indicates that all the model scenarios show a good fit for the data.

\subsection{Discussion}

\begin{tabular}{|l|c|}
\hline \multicolumn{1}{|c|}{ Hypothesis } & Decision \\
\hline $\begin{array}{l}\text { H1: Relative advantages of blockchain technology has a positive } \\
\text { influence on Malaysian higher education institutes intention to adopt } \\
\text { blockchain technology. }\end{array}$ & Rejected \\
\hline $\begin{array}{l}\text { H2: Perceived ease of use has a positive influence on Malaysian higher } \\
\text { education institutes intention to adopt blockchain technology. }\end{array}$ & Rejected \\
\hline $\begin{array}{l}\text { H3: Perceived usefulness has a positive influence on Malaysian higher } \\
\text { education institutes intention to adopt blockchain technology. }\end{array}$ & Accepted \\
\hline $\begin{array}{l}\text { H4: Scalability concerns of blockchain technology has a negative } \\
\text { influence on Malaysian higher education institutes intention to adopt } \\
\text { blockchain technology. }\end{array}$ & Rejected \\
\hline $\begin{array}{l}\text { H5: Top management support has a positive influence on Malaysian } \\
\text { higher education institutes intention to adopt blockchain technology. }\end{array}$ & Accepted \\
\hline $\begin{array}{l}\text { H6: Competitive pressure from the rivals, has a positive influence on } \\
\text { Malaysian higher education institutes intention to adopt blockchain } \\
\text { technology. }\end{array}$ & Accepted \\
\hline $\begin{array}{l}\text { H7: Supportive regulatory policies have a positive influence on } \\
\text { Malaysian higher education institutes intention to adopt blockchain } \\
\text { technology. }\end{array}$ & Rejected \\
\hline
\end{tabular}

Figure 2 Hypothesis decision

Decision regarding the hypothesis has been summarized. Multiple regression analysis was conducted to test the constructed hypothesis. The regression model explains $62.7 \%$ of the variance for the dependent variable (Blockchain adoption), this indicates that, more than half of the variance has been explained by the predictors, for the Malaysian higher education institutes intention to adopt Blockchain technology. Overall the regression model was a good fit, with a significance value of ( $\mathrm{p}<$ 0.0001). Based on the results of the regression model, 4 hypotheses $(\mathrm{H} 1, \mathrm{H} 2, \mathrm{H} 4$ and $\mathrm{H} 7)$ were rejected due to the unsatisfactory statistical support, while 3 hypotheses (H3, H5 and H6) were accepted due to the significant statistical support.

\subsubsection{Theoretical implications}

In the technological context of the proposed research framework, Relative advantages factor was perceived to have a positive influence on Malaysian higher education institutes intention to adopt Blockchain technology (H1). Based on the results of statistical analysis, (H1) was rejected as the "beta" coefficient value of relative advantages (RA) was (-2.040), which indicates that relative advantages of Blockchain technology negatively influence Blockchain adoption in higher education institutes of Malaysia. This is not consistent with the studies, that have identified relative advantages as a positive factor for Blockchain adoption in the higher education institutes [45], [63]-[65]. Relative advantage of a technology provides a motivational base for the adoption process of an innovation in the organization, as the users and management consider that, relative advantages will enhance their work efficiency [66].

Relative advantage of a technology is usually considered as a positive influencer of an adoption process, but relative advantage was observed to have a significant negative influence on Malaysian higher education institutes intention to adopt Blockchain technology. There can be multiple reasons for this conflictive finding, although universities do realize the perceived benefits of the Blockchain technology, but they might have lower level of Blockchain expertise and knowledge. Another possible reason can be, that Blockchain technology is a new technology in this industry, and has a complex implementation mechanism. Also, universities might have considered the cost of implementing Blockchain technology, as the high cost of implementing a certain technology can act as a barrier to its adoption process [67]. A study by [68], identified relative advantage factor as being the negative influencer in the adoption process. Their findings concluded, that relative advantage can act as a barrier to adoption mechanism in an organization only if, the technology is relatively new and its implementation is perceived as costly. Although Blockchain technology has many potential benefits such as transparency and interconnectivity [20], [22], yet higher education institutes of Malaysia do not consider it more advantageous than other operational technologies.

Perceived ease of use factor was noted to have a significant positive influence on technology adoption based in the previous published literature. Hypothesis (H2) was rejected, based on the statistical analysis that resulted negative "beta" coefficient (-.504) value of variable perceived ease of use. This resulted, as a negative influence of perceived ease of use on Malaysian higher education institutes intention to adopt Blockchain. These findings are not consistent with the studies that have identified perceived ease of use as the positive determinant of technology adoption process in the higher education institutes [49], [69]-[71].

Although perceived ease of use has been identified as the significant factor, but higher education institutes of Malaysia consider Blockchain applications and systems as difficult to operate. These findings imply that, some innovations and technologies are easier to understand and operate, while other technologies might require some extra effort and knowledge [72]. Also, the relation between perceived ease of use and Blockchain adoption in higher education institutes of Malaysia might have been mediated by other factors such as user experience 
and user characteristics [73]. Thus, further research is required, with the inclusion of mediating factors to determine the direct relation between perceived ease of use and Blockchain adoption.

Although the statistical value indicates that scalability concerns has a negative influence on Blockchain adoption, but still it is not significant enough to predict Malaysian higher education institutes intention to adopt Blockchain technology. This result is not consistent with the previous studies, which has identified that, scalability is one of the major concern of Blockchain technology and its wide applicability across various industries [50]. Blockchain processes approximately 7 transactions per second, which is considered as very low for its application in different industries and their respective applications [74]. Previous studies have identified that, Malaysian government is taking notable steps to regulate Blockchain and motivate higher education institutes to adopt Blockchain technology [15], [18].

Users consider technology useful, if with the use of technology their work efficiency and performance increases [75]. Use of Blockchain technology is perceived useful, as it can impact, performance of the university and its user's in multiple ways. Blockchain can benefit, Malaysian higher education institutes in context of storing education data in the digital form, which can be transparent and decentralized. Also, universities of Malaysia are faced with a challenge of certificate forgery, and Blockchain has the potential to overcome this challenge, as universities can issues certificates and degrees based on Blockchain platform. Such platforms are already functional and universities are issuing certificates by utilizing Blockchain technology[20], [22].

Top management support is essential in the higher education sector, regarding the mechanism of innovation adoption. As, top management decides which technology and innovation, they will adopt for their strategic and educational purposes [76]. Decision makers in the higher education institutes are usually the top management, and their decision and evaluation are the key in deciding whether they will adopt certain technology or not. Top management supports an adoption process of a new technology like Blockchain, by providing necessary resources and funding for its implementation and integration with the current systems and also motivating its users for accepting the technology adoption process. In Malaysian two universities have already adopted Blockchain technology for their degree verification and issuance process [13].

Hypothesis (H7) refers to the regulatory policies of Blockchain technology with respect to Malaysian higher education institutes. Regulatory policies of Blockchain are perceived to be supportive, so, it has a positive influence on Malaysian higher education institutes intention to adopt Blockchain technology. Based on the statistical analysis, regulatory policies of Blockchain technology were not found as a significant $(\mathrm{p}=.794)$ determinant of its adoption for Malaysian higher education institutes. Although previous studies have identified that, Malaysian government is taking notable steps to regulate Blockchain and motivate higher education institutes to adopt Blockchain technology [15], [18]. Still yet, Malaysian government is in the early phase of regulating Blockchain, due to its changing environment [14]. This can be one of the major reasons that, respondents do not consider regulatory policy as the determinant of Blockchain technology in the higher education sector of Malaysia. Also, as the Blockchain technology is currently in its infancy phase of being implemented across various industries[77], [78], this might be a reason that Malaysian higher education institutes do not want to take a risk of adopting a technology that is currently new, due to the perceived risks. Hence, there is a need to research more on regulatory policy of Blockchain technology, to achieve a consensus of whether it will determine its adoption in the higher education sector.

Adopting Blockchain technology can be a source of innovation for the universities to improve their business process and decision making capability [5]. While keeping in view, that few Malaysian universities are interested in adopting Blockchain technology [13], [17], and with that universities that will implement Blockchain might have certain edge in their industry environment. As already established, employers will have trust on the certificates issued by the respective university and this will increase overall reputation of the university in the industry and higher education sector. Higher education institutions compete on the basis of their educational services, IT infrastructure and quality of their output [79]. Hence, it becomes essential for higher education institutes to adopt disruptive technologies like Blockchain to sustain in the competitive environment.

\subsubsection{Managerial implications}

Management of the non-adopter and adopter universities in Malaysia can take advantage of the review, by focusing on the potential applications that have already been developed and utilized by other higher education institutes. While proposed use-cases of Blockchain identified in the literature, can be further tested to evaluate their significance for the higher education institutes services perspective. Perceived usefulness is identified as one of the important variables for Malaysian higher education institutes intention to adopt Blockchain technology. Thus, this implies that, decision-makers of the universities who want to operationalize Blockchain technology, should inform their user's and employees regarding the usefulness of Blockchain technology and how it can impact their overall work performance. As, once the potential benefits will be realized by the users of the technology, they will 
be motivated to adopt it [80], and this will increase their overall satisfaction level for the respective technology.

It is a reason to perceive that intention towards the adoption of a technology will transform over time. Considering that Blockchain is a disruptive technology, it is obvious that, with time more potential use-cases of Blockchain for higher education sector will be identified and that might cater the respective business and educational needs of the universities. This is consistent with the study of [81], where they mentioned four different phases of adoption, and fourth phase deals with transformation. It is perceived that, Factors influencing Blockchain adoption will be different in transformation phase than in the other early phases (initial use or substitutional phase). This implies that, once the users are more expert and educated, perceived ease of use and relative advantage variable might come up as more significant and positive influencer of Blockchain adoption in the context of higher education institutes of Malaysia.

\section{CONCLUSION AND FUTURE SCOPE}

Organizations are constantly adapting their practices to sustain and stay ahead of the current complex and dynamic business environment. Higher education sector of Malaysia has evolved as an economy-driven entity for Malaysian government. This has enforced a fierce competition in the higher education sector of Malaysia. Universities are focusing more on research activities and innovations to stay ahead in the changing business environment. Blockchain technology can revolutionize the practices and services offered by the higher education institutes. Blockchain technology offers certain advantages to this sector, such as, greater transparency, improved traceability and enhanced security. Various universities around the world are taking advantage of these features of Blockchain technology. Yet, higher education institutes of Malaysia lack behind in adopting Blockchain technology. This is the motivation behind this research, to identify and evaluate determinants (enablers or barriers) of Blockchain technology that can influence Malaysian higher education institutes intention to adopt it.

Predictor variables in the research were relative advantages, perceived ease of use, perceived usefulness, scalability concern, top management support, competitive pressure and regulatory policy and dependent variable was Blockchain adoption. Based on the findings from the conducted statistical analysis three hypothesis were accepted from the constructed seven hypothesis. Perceived usefulness, top management support and competitive pressure were identified as the significant factors that would influence Malaysian higher education institutes intention to adopt Blockchain technology. While, competitive pressure was identified as the most significant factor for this research.
Furthermore, the proposed framework explains, $62.7 \%$ of the variance for the Malaysian higher education institutes intention to adopted Blockchain technology.

Integrating more external variables to this framework might increase the variance to be explained for Blockchain adoption. Hence, it is suggested to evaluate more external variables in the context of technology, organization and environment for studying Blockchain adoption. It was greatly noted that, experience and knowledge regarding the technology plays a key role in determining the effect of external predictors on Blockchain adoption. It is recommended to add experience and knowledge components as the mediating variables for studying the Blockchain adoption likelihood. Relative advantage and perceived ease of use resulted an opposite effect on Blockchain adoption and were not consistent with the previous studies. Further research can be conducted on these variables to generalize their influence on Blockchain adoption. This research was conducted on five Malaysian universities, hence, considering more universities might result in more consistent findings. While, this research is limited to Malaysian higher education sector, future research could look into other sample countries to highlight differences and similarities with respect to Blockchain adoption. It is perceived that, different business environment, regulations and cultures might result in different determinants of Blockchain adoption. Furthermore, Blockchain technology is relatively new and is maturing as an innovation, so the determinants of Blockchain adoption might change during this phase. Further research with respect to Blockchain adoption is exciting and required.

\section{REFERENCES}

[1] C. A. de Mattos and F. J. B. Laurindo, "Information technology adoption and assimilation: Focus on the suppliers portal," Comput. Ind., vol. 85, pp. 48-57, 2017.

[2] A. Owusu, A. Ghanbari-Baghestan, and A Kalantari, "Investigating the Factors Affecting Business Intelligence Systems Adoption: A Case Study of Private Universities in Malaysia," Int. J. Technol. Diffus., vol. 8, no. 2, pp. 1-25, 2017.

[3] D. Kabakchieva, "Business intelligence systems for analyzing university students data," Cybern. Inf. Technol., vol. 15, no. 1, pp. 104-115, 2015.

[4] P. K. Paul, A. Bhuimali, and P. S. Aithal, "Indian Higher Education: With Slant to Information Technology - A Fundamental Overview," Int. J. Recent Res. Sci. Eng. Technol., no. November, pp. 30-50, 2017. 
[5] F. Milani, L. García-Bañuelos, and M. Dumas, "Blockchain and Business Process Improvement," BPTrends, p. 4, 2016.

[6] S. Nakamoto, "Bitcoin: A Peer-to-Peer Electronic Cash SyNakamoto, S. (2008). Bitcoin: A Peer-toPeer Electronic Cash System. Consulted, 1-9. doi:10.1007/s10838-008-9062-0stem," J. Gen. Philos. Sci., vol. 39, no. 1, pp. 53-67, 2008.

[7] I.-C. Lin, “A Survey of Blockchain Security Issues and Challenges," Int. J. Netw. Secur., vol. 1919, no. 55, pp. 653-659, 2017.

[8] S. A. Abeyratne, "Blockchain Ready Manufacturing Supply Chain Using Distributed Ledger," Int. J. Res. Eng. Technol., vol. 5, no. 9, pp. 1-10, 2016.

[9] Swan, "Blockchain - O'Reilly Media," O’Reilly Media, 2015. [Online]. Available: http://shop.oreilly.com/product/0636920037040.do . [Accessed: 16-Oct-2018].

[10] R. Craig, "How Blockchain Can Truly Revolutionize Higher Education," 2018. [Online]. Available:

https://www.forbes.com/sites/ryancraig/2018/02/22 /how-Blockchain-can-truly-revolutionize-highereducation/\#e99c28526b73. [Accessed: 07-Dec2018].

[11] G. Joseph, "Malaysia is Now Using Blockchain to Combat Fake Degree Certificates - BTCNN," 2018. [Online]. Available: https://www.btcnn.com/Blockchainnews/malaysia-is-now-using-Blockchain-tocombat-fake-degree-certificates/. [Accessed: 07Dec-2018].

[12] A. Kandasivam, "Blockchain: creating evolution or revolution in the education sector? | Digital News Asia," 2018. [Online]. Available: https://www.digitalnewsasia.com/digitaleconomy/Blockchain-creating-evolution-orrevolution-education-sector. [Accessed: 07-Dec2018].

[13] A. Abas, "University consortium set up to authenticate degrees using Blockchain technology | New Straits Times | Malaysia General Business Sports and Lifestyle News," 2018. [Online]. Available: https://www.nst.com.my/news/nation/2018/11/429 615/university-consortium-set-authenticatedegrees-using-Blockchain. [Accessed: 07-Dec2018].

[14] E. Karim, A. B. Munir, and R. Kok, "MALAYSIAN BLOCKCHAIN REGULATORY REPORT,” 2018.
[15] N. Husna Zakaria, S. Kunhibava, and A. Bakar Munir, "Prospects and Challenges: Blockchain Space in Malaysia," 2018.

[16] D. Nestarcova, "Report on Malaysian Blockchain Regulatory Report Launch and Forum Forum Report," 2018.

[17] M. A. Ameedeen, "Blockchain: Chain of trust Tech News | The Star Online," 2018. [Online]. Available: https://www.thestar.com.my/tech/technews/2018/03/26/Blockchain-chain-of-trust/. [Accessed: 08-Dec-2018].

[18] A. Harris and M. Al-Imam, "Blockchain Technology Malaysia: Revolutionising the industry @ Limkokwing University of Creative Technology," 2018. [Online]. Available: https://www.limkokwing.net/kuala_lumpur/news/a rticle/Blockchain_technology_malaysia_revolution ising_the_industry. [Accessed: 08-Dec-2018].

[19] J. Nazaré and K. Hamilton, "Digital Certificates Project," 2015. [Online]. Available: http://certificates.media.mit.edu/. [Accessed: 15Oct-2018].

[20] P. Sarda, M. J. M. Chowdhury, A. Colman, M. A. Kabir, and J. Han, "Blockchain for Fraud Prevention: A Work-History Fraud Prevention System," 2018 17th IEEE Int. Conf. Trust. Secur. Priv. Comput. Commun. 12th IEEE Int. Conf. Big Data Sci. Eng., pp. 1858-1863, 2018.

[21] F. Bond and G. Blousson, "Blockchain, academic verification use case," 2015.

[22] F. Amati, "First official career diplomas on Bitcoin's Blockchain," 2015. [Online]. Available: https://blog.signatura.co/first-official-careerdiplomas-on-bitcoin-s-Blockchain-69311acb544d. [Accessed: 15-Oct-2018].

[23] W. Egbertsen, G. Hardeman, M. Van Den Hoven, G. Van Der Kolk, and A. Van Rijsewijk, "Replacing Paper Contracts With Ethereum Smart Contracts," pp. 1-35, 2016.

[24] I. Britche, "Britchenko I . Protects innovative technologies into educational system introduction / P .," 2018.

[25] S. Acharya and J. Dunn, "Overstock. com ventures into digital currencies,” J. Bus. Cases Appl. Vol., vol. 12, 2015.

[26] P. Williams, "Does competency-based education with Blockchain signal a new mission for universities?,” J. High. Educ. Policy Manag., vol. 0, no. 0, pp. 1-14, 2018. 
[27] A. Mikroyannidis, M. Bachler, J. Domingue, and K. Quick, "A Learner-Centred Approach for Lifelong Learning Powered by the Blockchain," Open Univ. Repos. Res. Publ. other Res. outputs, 2018.

[28] Broggi, Lilly, and Duquette, "Building the first Blockchain university," Woolf Dev. Ltd, no. August, 2018.

[29] M. Jirgensons and J. Kapenieks, "Blockchain and the Future of Digital Learning Credential Assessment and Management," J. Teach. Educ. Sustain., vol. 20, no. 1, pp. 145-156, 2018.

[30] Schmidt, "Certificates, Reputation, and the Blockchain - MIT MEDIA LAB - Medium,” 2015. [Online]. Available: https://medium.com/mitmedia-lab/certificates-reputation-and-the-

Blockchain-aee03622426f. [Accessed: 17-Oct2018].

[31] A. Grech and A. F. Camilleri, "Blockchain in Education," Publ. Off. Eur. Union 2017, 132 S. (JRC Sci. Policy Report), 2017.

[32] J. Shaobo, "A Comprehensive Review of Research in IT Adoption," IEEE Access, vol. 11, no. 1, pp. 98-105, 2008.

[33] M. D. Williams, Y. K. Dwivedi, B. Lal, and A. Schwarz, "Contemporary trends and issues in IT adoption and diffusion research," J. Inf. Technol., vol. 24 , no. 1, pp. 1-10, 2009.

[34] Y. Liu et al., "FooDNet: Toward an Optimized Food Delivery Network based on Spatial Crowdsourcing," IEEE Trans. Mob. Comput., vol. 1233, no. c, pp. 1-1, 2018.

[35] W. R. King and J. He, "A meta-analysis of the technology acceptance model," Inf. Manag., vol. 43, no. 6, pp. 740-755, 2006.

[36] P. R. Palos-Sanchez, "Cloud Computing (SaaS) Adoption as a Strategic Technology: Results of an Empirical Study,” Mob. Inf. Syst., vol. 2017, 2017.

[37] A. S. Carr, M. Zhang, I. Klopping, and H. Min, "RFID Technology: Implications for Healthcare Organizations," Am. J. Bus., vol. 25, no. 2, pp. 2540, 2010.

[38] Y. M. Wang, Y. S. Wang, and Y. F. Yang, "Understanding the determinants of RFID adoption in the manufacturing industry," Technol. Forecast. Soc. Change, vol. 77, no. 5, pp. 803-815, 2010.

[39] Y. Alshamaila and F. Li, "Cloud computing adoption by SMEs in the north east of England: A multi-perspective framework," J. Enterp. Inf. Manag., vol. 26, no. 3, pp. 250-275, 2013.
[40] F. Alharbi, "Decision makers views of factors affecting cloud computing adoption in saudi healthcare organisations," 2017 Int. Conf. Informatics, Heal. Technol. ICIHT 2017, vol. 2, no. 3, pp. 155-171, 2017.

[41] H. Gangwar and R. Ramaswamy, "Understanding determinants of cloud computing adoption using an integrated TAM-TOE model," J. Enterp. Inf. Manag., vol. 28, no. 1, pp. 107-130, 2015.

[42] K.-W. Wen and Y. Chen, "E-business value creation in Small and Medium Enterprises: a US study using the TOE," Int. J. Electron. Bus., vol. 8, no. 1, pp. 80 100,2010

[43] T. Oliveira and M. Thomas, "Assessing the determinants of cloud computing adoption: An analysis of the manufacturing and services sectors," Inf. Manag., vol. 51, no. 5, pp. 497-510, 2014.

[44] K. Zhu, S. Dong, S. X. Xu, and K. L. Kraemer, "Innovation diffusion in global contexts: Determinants of post-adoption digital transformation of European companies," Eur. J. Inf. Syst., vol. 15, no. 6, pp. 601-616, 2006.

[45] A. N. Tashkandi and I. M. Al-Jabri, "Cloud computing adoption by higher education institutions in Saudi Arabia: Analysis based on TOE," Cluster Comput., vol. 18, no. 4, pp. 1527-1537, 2015.

[46] I. M. Al Jabri, "Factors affecting cloud computing adoption: perspectives of IT professionals," Int. J. Bus. Inf. Syst., vol. 23, no. 4, p. 389, 2016.

[47] Y. A. M. Qasem, R. Abdullah, R. Atan, and Y. Y. ah Jusoh, "Towards Developing a Cloud-Based Education As a Service (Ceaas) Model for Cloud Computing Adoption in Higher Education Institutions," Acta Inform. Malaysia, vol. 2, no. 2, pp. 19-20, 2018.

[48] K. Rahimah, A. H. N. Aziati, H. B. Adnan, H. Adly, M. Noor, and F. A. Rahman, "Organization Support for Cloud Computing Implementation Success in Education System: Scale Development and Validity in Delphi," Int. J. Eng. Technol., vol. 7, no. September, 2018.

[49] Z. Gholami, M. Abdekhoda, and V. Z. Gavgani, "Determinant factors in adopting mobile technology-based services by academic librarians," DESIDOC J. Libr. Inf. Technol., vol. 38, no. 4, pp. 271-277, 2018.

[50] G. O. Karame, "On the Security and Scalability of Bitcoin's Blockchain,” ACM ISBN 978-1-45034139-4/16/10., pp. 24-28, 2016. 
[51] E. Androulaki, "Double-Spending Fast Payments in Bitcoin," Proc. 22nd ACM SIGSAC Conf. Comput. Commun. Secur. - CCS ’15, pp. 906-917, 2015.

[52] A. Gervais and H. Ritzdorf, "Tampering with the Delivery of Blocks and Transactions in Bitcoin," Proc. 22nd ACM SIGSAC Conf. Comput. Commun. Secur. - CCS '15, pp. 692-705, 2015.

[53] A. Gervais, G. O. Karame, V. Capkun, and S. Capkun, "Is Bitcoin a Decentralized Currency?," IEEE Secur. Priv., vol. 12, no. 3, pp. 54-60, 2014.

[54] L. Riungu-Kalliosaari, Empirical study on the adoption, use and effects of cloud-based testing, no. June. 2012.

[55] M. Barkhordari, Z. Nourollah, H. Mashayekhi, Y. Mashayekhi, and M. S. Ahangar, "Factors influencing adoption of e-payment systems: an empirical study on Iranian customers," Inf. Syst. Ebus. Manag., vol. 15, no. 1, pp. 89-116, 2017.

[56] A. Jencik, "Qualitative versus quantitative research," 21st Century Polit. Sci. A Ref. Handb., pp. 506-513, 2011.

[57] R. Raut, "Understanding the Mediation Effect of Cloud Computing Adoption in Indian Organization," Int. J. Serv. Sci. Manag. Eng. Technol., vol. 8, no. 3, pp. 40-59, 2017.

[58] L. S.-L. Chen and J.-H. Chen, “Antecedents and optimal industrial customers on cloud services adoption,” Serv. Ind. J., vol. 0, no. 0, pp. 1-27, 2018.

[59] F. Holotiuk and J. Moormann, "Organizational Adoption of Digital Innovation: the Case of Blockchain Technology," Twenty-Sixth Eur. Conf. Inf. Syst., 2018.

[60] M. Tavakol and R. Dennick, "Making sense of Cronbach's alpha," Int. J. Med. Educ., vol. 2, pp. 53-55, 2011.

[61] M. H. Baturay, Ş. Gökçearslan, and F. Ke, "The relationship among pre-service teachers' computer competence, attitude towards computer-assisted education, and intention of technology acceptance," Int. J. Technol. Enhanc. Learn., vol. 9, no. 1, p. 1, 2017.

[62] L. Madariaga et al., "Online survey: A national study with school principals," Comput. Human Behav., vol. 74, pp. 35-44, 2017.

[63] K. Njenga, L. Garg, A. K. Bhardwaj, V. Prakash, and S. Bawa, "The cloud computing adoption in higher learning institutions in Kenya: Hindering factors and recommendations for the way forward," Telemat. Informatics, no. September, pp. 0-1, 2018.
[64] M. T. Amron, R. Ibrahim, and S. Chuprat, "A Review on Cloud Computing Acceptance Factors," Procedia Comput. Sci., vol. 124, pp. 639-646, 2017.

[65] J. W. Lian, D. C. Yen, and Y. T. Wang, "An exploratory study to understand the critical factors affecting the decision to adopt cloud computing in Taiwan hospital,” Int. J. Inf. Manage., vol. 34, no. 1, pp. $28-36,2014$.

[66] H. Gangwar, H. Date, and R. Ramaswamy, "Understanding determinants of cloud computing adoption using an integrated TAM-TOE model," J. Enterp. Inf. Manag., vol. 28, no. 1, pp. 107-130, 2015.

[67] T. S. H. Teo, S. C. Srivastava, and L. Jiang, "Trust and Electronic Government Success: An Empirical Study,” J. Manag. Inf. Syst., vol. 25, no. 3, pp. 99132, 2008.

[68] C. Low, Y. Chen, and M. Wu, "Understanding the determinants of cloud computing adoption," Ind. Manag. Data Syst., vol. 111, no. 7, pp. 1006-1023, 2011

[69] R. Arumugam, "The usage of technology among education students in University Utara Malaysia: An application of extended Technology Acceptance Model," Int. J. Educ. Dev. using Inf. Commun. Technol., vol. 7, no. 3, pp. 239-245, 2017.

[70] P. Ashok Kumar, "A study on adoption of Erecruitment using Technology Acceptance Model (TAM) with reference to graduating students in universities in Bahrain," Int. J. Adv. Res., vol. 2, no. 9, pp. 377-383, 2015.

[71] A. Tarhini, R. Masa'deh, A. Al-Badi, M. Almajali, and S. H. Alrabayaah, "Factors Influencing Employees' Intention to Use Cloud Computing," J. Manag. Strateg., vol. 8, no. 2, p. 47, 2017.

[72] M. A. Alajmi, "Predicting the Use of a Digital Library System: Public Authority for Applied Education and Training (PAAET)," Int. Inf. Libr. Rev., vol. 46, no. 1-2, pp. 63-73, 2014.

[73] M. Esen and Ni. Erdogmus, "Effects of Technology Readiness on Technology Acceptance in E-HRM: Mediating Role of Perceived Usefulness," J. Knowl. Manag., vol. IX, no. I, pp. 7-21, 2014.

[74] K. O'Dwyer and D. Malone, "Bitcoin mining and its energy footprint," ISSC 2014 / CIICT 2014, Limerick, June 26-27, 2014.

[75] E. Adewole-Odeshi, "Attitude of Students Towards E-Learning in South-West Nigerian Universities: An Application of Technology Acceptance Model,' 
Libr. Philos. Pract., no. January, p. Paper 1035, 2015.

[76] A. Alghushami, N. H. Zakaria, and Z. M. Aji, "The determinants impacting the adoption of cloud computing in Yemen institutions," AIP Conf. Proc., vol. 20022, 2016.

[77] J. L. Zhao and F. Shaokun, "Overview of business innovations and research opportunities in Blockchain and introduction to the special issue," Springer, vol. 15, no. 8, 2016.

[78] C. Berg, "Delegation and Unbundling in a CryptoDemocracy," Ssrn, no. July 2017, pp. 1-15, 2017.

[79] F. Ali and K. Pradeep, "Does higher education service quality affect student satisfaction, image and loyalty? A study of international students in Malaysian public universities Introduction," Qual. Assur. Educ., vol. 24, no. 1, 2016.

[80] J. Mou, D. H. Shin, and J. Cohen, "Understanding trust and perceived usefulness in the consumer acceptance of an e-service: a longitudinal investigation,” Behav. Inf. Technol., vol. 36, no. 2, pp. 125-139, 2017.

[81] K. R. Lakhani and M. Iansity, "the Truth About Blockchain," Harvard Bus. Rev., vol. 95, no. 1, pp. 119-127, 2017.

[82] Subramani, P., Rajendran, G.B., Sengupta, J., Pérez de Prado, R. and Divakarachari, P.B., 2020. A block bi-diagonalization-based pre-coding for indoor multiple-input-multiple-output-visible light communication system. Energies, 13(13), p.3466.

[83] Prabu, S., Lakshmanan, M. and Mohammed, V.N., 2019. A multimodal authentication for biometric recognition system using intelligent hybrid fusion techniques. Journal of medical systems, 43(8), pp.19.

[84] Sah, D.K., Nguyen, T.N., Cengiz, K., Dumba, B. and Kumar, V., 2021. Load-balance scheduling for intelligent sensors deployment in industrial internet of things. Cluster Computing, pp.1-13.

[85] Pham, V.T., Nguyen, T.N., Liu, B.H. and Lin, T., 2021, March. Minimizing latency for multiple-type data aggregation in wireless sensor networks. In 2021 IEEE Wireless Communications and Networking Conference (WCNC) (pp. 1-6). IEEE.

[86] Do, D.T., Van Nguyen, M.S., Nguyen, T.N., Li, X. and Choi, K., 2020. Enabling multiple power beacons for uplink of noma-enabled mobile edge computing in wirelessly powered IOT. IEEE Access, 8, pp.148892-148905.
[87] Fathima, N., Ahammed, A., Banu, R., Parameshachari, B.D. and Naik, N.M., 2017, December. Optimized neighbor discovery in Internet of Things (IoT). In 2017 International Conference on Electrical, Electronics, Communication, Computer, and Optimization Techniques (ICEECCOT) (pp. 1-5). IEEE.

[88] Shivappriya, S.N., Karthikeyan, S., Prabu, S., Pérez de Prado, R. and Parameshachari, B.D., 2020. A modified ABC-SQP-based combined approach for the optimization of a parallel hybrid electric vehicle. Energies, 13(17), p.4529.

[89] Vadivel, S., Konda, S., Balmuri, K.R., Stateczny, A. and Parameshachari, B.D., 2021. Dynamic Route Discovery Using Modified Grasshopper Optimization Algorithm in Wireless Ad-Hoc Visible Light Communication Network. Electronics, 10(10), p.1176.

[90] L. Tan, H. Xiao, K. Yu, M. Aloqaily, Y. Jararweh, "A Blockchain-empowered Crowdsourcing System for 5G-enabled Smart Cities", Computer Standards $\&$ Interfaces, https://doi.org/10.1016/j.csi.2021.103517

[91] L. Tan, N. Shi, K. Yu, M. Aloqaily, Y. Jararweh, “A Blockchain-Empowered Access Control Framework for Smart Devices in Green Internet of Things", ACM Transactions on Internet Technology, vol. 21, no. 3, pp. 1-20, 2021,https://doi.org/10.1145/3433542.

[92] K. Yu, L. Tan, M. Aloqaily, H. Yang, and Y. Jararweh, "Blockchain-Enhanced Data Sharing with Traceable and Direct Revocation in IIoT", IEEE Transactions on Industrial Informatics, doi: 10.1109/TII.2021.3049141.

[93] K. Yu, L. Tan, X. Shang, J. Huang, G. Srivastava and P. Chatterjee, "Efficient and Privacy-Preserving Medical Research Support Platform Against COVID-19: A Blockchain-Based Approach", IEEE Consumer Electronics Magazine, doi: 10.1109/MCE.2020.3035520. 